\title{
ENHANCING QUALITY OF EDUCATION: A CASE STUDY ON AN INTERNATIONAL ISLAMIC SCHOOL
}

\author{
Rafikul Islam ${ }^{*}$, Ibrahim Mohd. Haidoub², and Kazi Md. Tarique ${ }^{3}$ \\ ${ }^{1}$ Department of Business Administration, Kulliyyah of Economics and Management \\ Sciences, International Islamic University Malaysia, P.O. Box 10, \\ 50728 Kuala Lumpur, Malaysia \\ ${ }^{2}$ Graduate School of Management, IIUM Academy of Graduate and Professional Studies, \\ International Islamic University Malaysia, Jalan Gombak, \\ 53100 Kuala Lumpur, Malaysia \\ ${ }^{3}$ Southeast University, 64 Road No. 18, Block B, Banani, Dhaka-1213, Bangladesh \\ *Corresponding author: rislam@iium.edu.my
}

Published online: 20 March 2019

To cite this article: Islam, R., Mohd. Haidoub, I., and Md. Tarique, K. (2019). Enhancing quality of education: A case study on an international Islamic school. Asian Academy of Management Journal, 24(Supp. 1), 141-156. https://doi.org/10.21315/aamj2019.24.s1.10

To link to this article: https://doi.org/10.21315/aamj2019.24.s1.10

\begin{abstract}
Private secondary schools that want to gain a competitive edge need to search for effective and creative ways to attract, retain, and foster stronger relationships with students. The decision of selecting a school by the parents for their kids is based on a multitude of factors that differ from one society to another depending on its culture, economic status, religion, and others. The objective of the present research is to identify and prioritise the factors that can enhance the quality of education in an international Islamic school located in Kuala Lumpur from parents' perspective. The researchers employed both qualitative and quantitative approaches for data collection. The qualitative data were collected through interviewing 10 parents whose kids are currently enrolled in the school, while the quantitative data were collected through a questionnaire survey based on the Analytic Hierarchy Process (AHP). A thematic analysis and AHP were used for analysing the qualitative and quantitative data, respectively. Findings from the thematic analysis resulted in 19 factors; however, only 8 factors with higher frequency were selected to represent the factors expected to enhance the quality of education. The AHP analysis resulted in prioritising these eight factors according to parents' judgements. The results show that the Islamic environment represents the most desired factor, followed by quality of teachers and school discipline.
\end{abstract}

Keywords: Islamic education, secondary school, quality of education, prioritisation of factors, Analytic Hierarchy Process

(C) Asian Academy of Management and Penerbit Universiti Sains Malaysia, 2019. This work is licensed under the terms of the Creative Commons Attribution (CC BY) (http://creativecommons. org/licenses/by/4.0/). 


\section{INTRODUCTION}

Education is generally classified into three broad levels: primary, secondary, and tertiary or higher education. Primary education or elementary education which is initiated in primary school or elementary school is typically the first stage of compulsory education that comes between early childhood education and secondary education. The primary school years are an important phase, as they lay the foundation for the child's learning. Typically, primary education is provided in schools, where children stay in steadily advancing classes until they complete it and move on to high school/secondary school. Secondary education normally takes place in secondary schools after primary education and may be followed by higher education or vocational training. In some countries, only primary or basic education is compulsory, but secondary education is included in the compulsory list in most of the countries. On the other hand, higher education represents the level where the students optionally choose to study in colleges or universities to attain degree of specialisation in a specific area (Lycke \& Tano, 2017).

Regarding primary as well as secondary education, parents exhibit different expectations from schools for their children. Parents' satisfaction is strongly associated with school's effectiveness and students' achievements (Kool \& Bekkers, 2016). Parents' satisfaction has direct linkage with how parents perceive the quality of education of a typical school. The process of selecting a school by the parents depends on factors that differ from one society to another depending on its culture, economic status, religion, and others.

\section{LITERATURE REVIEW}

\section{School Choice Factors}

Parents are known as significant stakeholder of a school and the main decision makers when it comes to choosing a school for their child. The act of parents choosing their child's school has been an important element of school reform movements throughout the past decade. School choice aims to empower the respective parents to make decisions to place their child in a better performing school, if in a case the child's current school is not performing well.

Parents often have more than one reason why they choose a particular school for their child (Axford et al., 2015). Parents may choose a school due to academic and non-academic factors. The Carnegie Foundation for the Advancement of Teaching (1992) stated that a parent may choose the best school for their child based on 
non-academic factors, while some other studies (e.g., Fossey, 1994) show that academic quality of a school may be the prime determining factor behind school choice. When customers purchase a product or service, they choose and select a product or service that gives the finest comprehensive experience to them. Thus, when parents make a choice for a school for their child, the school in return is expected to provide a positive experience to the parent.

According to the Malaysian Ministry of Education, private schools in Malaysia are defined as "a school or an educational institution which is not a government or government-aided school or educational institution", as provided in the Malaysia Education Act (Government of Malaysia, 1996). In Malaysia, school choice is generally an option for parents that are of a more affluent demography as private school fees are higher than public schools and are mainly for parents that can afford the higher fees. Many parents seem to claim that private schools are much more capable of equipping their children in an era where challenges are abundant and exposure to the harsh realities of the world is done in a younger age (Kuswadi, Barakbah, \& Nuh, 2015).

Many parents also claim that they prefer private schools for their children as graduates of private schools are better in terms of self-confidence and social skills when compared to public school graduates (Kuswadi et al., 2015). According to the Malaysia Education Blueprint (2013-2025), private schools that are adopting the national curriculum seem to be performing better than public schools (Government of Malaysia, 2013). When parents explore options in choosing a school, they usually weigh all other options and put their trust on a particular school of their choice. However, an underperforming public school can be deserted by a parent for its lack of quality (Schumacher, 2011). A private school that does not seem to be living up to its expectations could be put under scrutiny by the parent and the parent may have a selection of other schools.

Burnham (1997) highlighted the following factors that were expected to enhance parents' satisfaction in schools: conformance to requirements, continuous improvement, responsiveness, integration, focus on delivery, and listening to customers. To enhance parental satisfaction, he suggested the school authorities to obtain feedback from the parents by varieties of means including suggestion cards, shadowing, interviews, surveys, and team meetings.

Golden and Smrekar (2009) carried out a project aimed at examining why and how parents make school choices, how involved and satisfied they are with their schools, and the dynamics of the choice process. The project focused on parents in one district in a large midwestern city, where their choices can be examined. 
It has looked specifically at parents' choice of magnet versus private schools. It has considered parents in charter schools and their perceptions of invitations to involvement from schools and teachers. The findings suggest that those who communicate frequently with their children are more involved in school. Results also show that income is a main factor in choosing a private school and that the more parents have access to social capital through informal networks, more likely they will consider private schools.

Malaysia is a predominantly Muslim country and there are many Islamic schools in the country, especially in and around Kuala Lumpur. However, there is a dearth of studies investigating the quality of the education provided by these institutions. Therefore, the present study aimed at shedding some light on how to ensure quality of education in one prominent Islamic school in Kuala Lumpur.

\section{AL-HILAL INTERNATIONAL ISLAMIC SCHOOL}

Al-Hilal International Islamic School ${ }^{1}$ (named as AH, for brevity) was established in 2008 in Kuala Lumpur. The school follows Cambridge curriculum and enjoys reasonably good reputation among the parents. The school has classes starting from Primary 1 until Cambridge A-level. Nearly 500 students are enrolled in the school at the time of conducting the present research (2017). However, retaining students is one of the major issues the school administration is facing today.

Like other educational institutions, the management team of AH seeks to attain the quality of teaching and learning that best fit its vision, mission, objectives, and values. As a private school, the management of $\mathrm{AH}$ represented by its marketing department is interested in increasing the number of enrolled students while maintaining the education quality. In fact, $\mathrm{AH}$ is operating in a moderately competitive market where few other schools are also operating that provide similar services as AH. Thus, increasing its market share while maintaining quality of education is a great challenge to $\mathrm{AH}$. Therefore, $\mathrm{AH}$ is interested in identifying the most important factors that can enhance quality of education and provide higher parental satisfaction. Hence, the main research questions are formulated:

RQ1: What are the factors that would enhance quality of education at AH?

RQ2: What are the priorities of the identified factors? 


\section{METHODOLOGY}

This study uses both qualitative and quantitative approaches to collect the necessary data. The qualitative part aimed at identifying the factors as per RQ1 while the quantitative approach focused on finding out the relative importance (prioritisation) of the factors (RQ2). The population of the study comprised the parents whose kids are currently enrolled in AH. The sample selected for our study was a purposive one because of the nature of the study. A sample of 10 parents was selected from the population who have diverse educational, national, and employment backgrounds. Data were collected through two common survey research instruments, namely interview and questionnaire.

\section{Interview}

The interview instrument was adopted to collect qualitative data to answer RQ1: What are the most relevant factors that would enhance quality of education in AH? A sample of 10 respondents (parents) was asked to answer an open-ended question pertaining to factors that are expected to enhance quality of education in AH. The conversations were then recorded and transcribed for each respondent. Transcribed data were then made ready for the purpose of analysis.

\section{Questionnaire}

A questionnaire was designed to collect quantitative data to answer RQ2. This questionnaire was designed according to a well-known decision-making method, the Analytic Hierarchy Process (AHP) (Saaty, 2008). Here AHP was chosen, as it is very suited to determine priorities of a set of factors. Ten respondents participated in the survey. Note that the sample size in AHP is usually small due to its inherent nature of the survey (Takala, Suwansaranyu, \& Phusavat, 2006). Three respondents from the sample that were selected to collect qualitative data were replaced by three new respondents who were more committed and involved with school programmes and instructions. This step will be elaborated further in the data analysis section.

\section{DATA ANALYSIS}

The data analysis for the present study was carried out in two sequential phases: qualitative followed by quantitative. Thematic analysis was used to analyse qualitative data whereas AHP method was used for quantitative data. 


\section{Thematic Analysis}

Braun and Clarke (2006) view thematic analysis as a qualitative analysis method for identifying, analysing, and reporting patterns (themes) within data. Thematic analysis of the data collected through interviews was employed to answer RQ1. The purpose was to generate themes from the ideas proposed by the respondents. Themes that emerge from repeated use of vocabulary, phrases, or concepts were classified into possible quality factors.

\section{AHP Data Analysis}

Having collected the AHP data through completed pairwise comparison matrices (PCMs), the following well-known steps of AHP were applied to derive the weights. As mentioned before, AHP data analysis answers RQ2.

Step 1: Calculate the geometric mean average PCMs for each category of respondents and considering all the respondents.

Step 2: Compute the weights of the factors by using the following rowcolumn normalisation process:

i. Sum the values in each column of the PCM.

ii. Divide each element in the matrix by its column total. The resulting matrix is referred to as the normalised pairwise comparison matrix.

iii. Compute the average of the elements in each row of the normalised matrix.

Step 3: Measure consistency in decision making process:

i. Multiply the first column by the weight of the first factor. Next multiply the second column by the weight of the second factor and so on. After this multiplication exercise, add the elements across the rows. This gives us a weighted sum vector.

ii. Divide each element of the weighted sum vector by the weights of the factors. First element should be divided by the weight of the first factor and so on. This division exercise gives the consistency vector. 


\section{RESULTS AND DISCUSSION}

This section presents the findings of the data analysis carried out in two distinct phases. The first phase was a thematic analysis on qualitative data, whereas AHP data analysis was carried in the second phase. The details of both phases are provided below.

\section{Results of Thematic Analysis}

The researchers applied the thematic analysis method for the data collected from 10 respondents. They were asked to provide ideas/suggestions on how AH can improve the quality of education provided by the school. Using the principle of thematic analysis, as prescribed by Braun and Clark (2006), the researchers identified 19 factors that can enhance quality of education at AH. Table 1 provides the names and corresponding frequencies of these 19 factors. For the purpose of further analysis using AHP, the researchers selected only eight factors from the list. The reason for this short listing is that only the factors having higher frequencies ( 5 and above) were considered and also to perform AHP analysis; the number of factors should be within the range of $7 \pm 2$ (Saaty, 2008). These eight factors are Islamic education, school discipline, quality of teachers, medium of instructions, communication with parents, class size, school curriculum, and school facilities.

Table 1

Findings from thematic analysis

\begin{tabular}{llcclc}
\hline$\#$ & Factors & Freq. & $\#$ & Factors & Freq. \\
\hline 1 & Islamic environment & 9 & 11 & Equality & 3 \\
2 & School discipline & 7 & 12 & School calendar & 3 \\
3 & Quality of teachers & 7 & 13 & Teaching methods & 2 \\
4 & Medium of instruction & 6 & 14 & Staff's effective communication & 2 \\
5 & Parents' involvement & 5 & 15 & Students' performance appraisal & 2 \\
6 & Class size & 5 & 16 & Stability of teachers & 2 \\
7 & School curriculum & 5 & 17 & Quality of administrative services & 1 \\
8 & School facilities & 5 & 18 & Administrative staff stability & 1 \\
9 & Students' learning outcomes & 3 & 19 & Effective internal coordination & 1 \\
10 & Teachers' effective communication & 3 & & & \\
\hline
\end{tabular}


The various ideas under the eight themes are provided below:

1. Islamic environment

- My kids should know their rights to Allah

- My kids to be Hafiz of Qur'an

- I was looking for Islamic school

- Memorisation and recitation of Qur'an

- Separate boys from girls

- Teaching Qur'an and performing night prayers activity

- Healthy ethical environment

- Students to learn Arabic as a language of Qur'an

- Teach students Islamic knowledge

- Searching for simple living, Islamic and ethical environment

- School that provides Islamic activities has an opportunity to build a real Muslim

- Provide qiyamullaill (night prayers) activity

- Islamic environment is not met because boys are not separated from girls in the class

2. Quality of teachers

- Teachers should give the best to students

- Difficulty in selecting teachers and most of them are students

- Highly supportive and cooperative teachers

- Good standards of teachers

- Selection of qualified teachers

- Teachers at lower grades fail to control and inspire students

- Teachers' skills and abilities

3. School discipline

- Discipline is more important than study

- Train children to know proper things and help themselves

- Discipline affects students' behaviour

- Discipline has to be number one

- Discipline should be satisfactory

- Without discipline students are not behaving in the right way 
- Discipline means rules and regulations have to be followed by students

- Students should be driven ethically by school

4. Medium of instruction

- AH teaches some subjects in Arabic although the formal medium is English

- I might think to drop out if they continue to teach some subjects in Arabic and ignore the English language as a formal communicative language

- Poor English language of some teachers and staff

5. Parents' involvement

- Involving parents of girls in night prayers activity

- Expectations are not achieved due to lack of parents' involvement

- Participation of parents in the annual meeting is not well planned

- Parents should be notified about any activity

- Importance of electronic communication between parents and school

- Lack of proper integration between parents and school

- Want to be well informed about the academic status of our sons

6. Class size

- Reasonable number of students in classroom

- Number of students should be relevant to the available capacity of teachers

- Class area is so small compared to class size

- Classroom is not spacious

- Present class size impedes effective communication

- Excessive number of students in class prevents teachers from controlling the class

7. School curriculum

- Terms of curriculum is very important

- Compare between different curricula

- British curriculum is an opportunity for my son to improve knowledge and benefit from better education system

- AH teaches British Empire and stories that are non-Islamic 
8. School facilities

- School infrastructure is not sufficient

- Building is not satisfactory as an international school

- School playground is not spacious

\section{Results of AHP Data Analysis}

The AHP respondents were asked to fill up a blank PCM using the Saaty 1-9 ratio scale. Each respondent filled up the matrix individually, as the data were collected from individual parents separately. Later, those 10 PCMs were averaged out by adopting the geometric means procedure as illustrated by Saaty and Peniwati (2008). From the average PCM, weights were extracted using row-column normalisation procedure. The average weights obtained from the normalised PCM provide the priorities of the factors. Table 2 shows the weights and corresponding ranks of the eight factors. The weights show that the most important factor is "Islamic environment" and the least important factor in the list is "class size".

Table 2

Weights of the eight factors

\begin{tabular}{lcc}
\hline Factors & Weights & Rank \\
\hline F1: Islamic environment & 0.32 & 1 \\
F3: Quality of teachers & 0.19 & 2 \\
F2: School discipline & 0.13 & 3 \\
F7: School curriculum & 0.11 & 4 \\
F5: Parents involvement & 0.09 & 5 \\
F4: Medium of instruction & 0.08 & 6 \\
F8: School facilities & 0.05 & 7 \\
F6: Class size & 0.04 & 8 \\
\hline
\end{tabular}

\section{Results Based on Demography of Respondents}

The weights of the eight factors were calculated separately for various levels of three demographical variables, namely nationality (Arabs and non-Arabs), employment (business owners and non-business owners), and qualification (bachelors and masters). The factors and their corresponding weights and ranks are provided in Table 3 for all levels of the three demographical variables mentioned above. Spearman's rank correlation coefficients (RCC) were computed for various levels of demographical factors and these are shown in the last row of Table 3. 


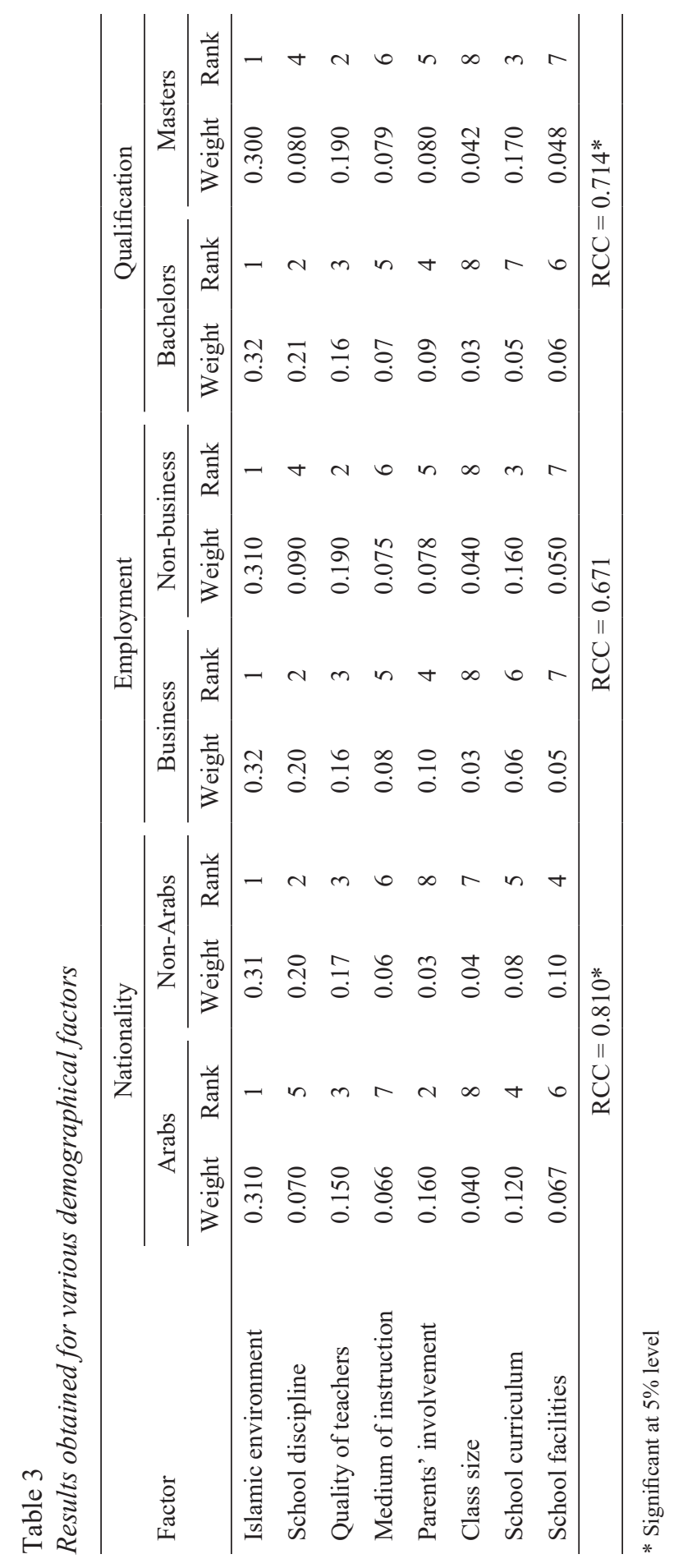


Except Arabs and non-Arabs pair, the RCCs of other two pairs were statistically significant at $5 \%$ level. Therefore, overall, the ranks generated for various categories of respondents were deemed to be similar.

\section{Discussion on the Findings}

Parents' satisfaction is an important matter for AH to achieve sustainability and growth in providing Islamic education. The AH administration must work with parents in a collaborative manner to enhance quality of the education provided by them. That is, AH is advised to be highly parents-oriented school and to maintain effective communication with them to gain their loyalty and commitment, and this also will eventually help AH to sustain their business in the long run. A brief description of the factors provided by the parents is provided below.

\section{Islamic environment}

The main reason for which Muslim parents send their kids to an Islamic school is the presence of an Islamic environment. Islamic environment means that the Muslim kids in that school can regularly perform their prayers and execute other Islamic activities provided by the school, interact ethically with others, and are protected from being exposed to rogue elements such as drugs, alcohol, or violence. In addition, Islamic schools are a place to build identity and security. Islamic atmosphere in $\mathrm{AH}$ is not only the first and utmost requirement by parents, but it is vividly articulated in its vision and clearly targeted in its mission. Thus, for $\mathrm{AH}$ to meet this first priority, it is expected that the school administration to pay sufficient attention to this issue and engage continuous efforts including the financial aspects so that it can meet parents' expectations.

\section{Quality of teachers}

Teacher's qualifications include a range of variables such as the type of teaching certification, specialisation area, and years of teaching experience. The selection of qualified and professional teachers is an extremely important task for education institutions. Assessing teachers on certain measures such as students' achievement and performance is a complicated process which involves controlling other factors such as the influence of parents, school environment, and the social context as a whole. Parents' opinions state that most AH teachers are merely international post graduate students who came to Malaysia for study purposes and according to them this matter is responsible for the high turnout of teachers. Therefore, AH must look into appointing qualified teachers who can stay at the school for a longer time. 


\section{School discipline}

School discipline comprises rules and regulations of the school including students' behavioural norms and how these are enforced and practiced. Strict rules are necessary to control students' actions and behaviour. Hence, school discipline, as a third priority for parents, is a good indicator of how much a school's rules and regulations affect the learning outcomes of the kids, their personality and behaviour. Without school discipline, AH will find difficulty to meet the factor of highest priority - the Islamic environment.

\section{School curriculum}

School curriculum in AH is a combination of Western curriculum, particularly the Cambridge programme, and Islamic knowledge and teaching of Arabic language. $\mathrm{AH}$ is advised to be clear about the curriculum which is based on Islamic theology and ethics.

\section{Parents' involvement}

Parents' involvement is an important means through which school administration can know the effectiveness of their strategies and policies. It also plays a great role in carrying out Islamic activities and school discipline. At AH, some parents complain that the school administration is oblivious to their expectations and suggestions. Therefore, AH is advised to regularly keep in touch with the parents. This will also enable the parents to know their kids' achievement and performance at the school.

\section{Medium of instructions}

The formal medium of instructions in $\mathrm{AH}$ is English but some parents complain about the poor communication style of some teachers and administrative staff. Despite the fact that parents consider teaching and practicing Arabic language in $\mathrm{AH}$ as an advantage for their kids, but ineffective communication might affect parents' involvement and lead to poor integration between school and parents. Hence, $\mathrm{AH}$ is advised to ensure that staff and teachers are able to communicate effectively with the students and their parents. 


\section{School facilities}

According to parents, the current building of AH is not sufficient to absorb the growing students' population and this might affect the school's ability to control the crowd of students. Thus, AH management is advised to find out another building with spacious area for classrooms, central library, laboratories, and playground and with the possibility of future expansions.

\section{Class size}

Parents view that the present large class size at $\mathrm{AH}$ in several classes might affect teachers' ability in communicating and controlling the classes. Thus, class size is another issue that requires attention on the part of the $\mathrm{AH}$ administration.

\section{IMPLICATIONS OF THE STUDY}

The AHP method has been found to be appropriate to prioritise the factors that can enhance quality of education at AH. The present AHP exercise can be extended further by applying it in other areas as well. For example, AHP can be applied to prioritise action plans to implement the policies recommended in the present study. On the other hand, the study underscores the importance of working with parents and develop a "working together" attitude so that the school can move forward and fulfil the objectives of the school as well as the parents.

\section{CONCLUSION}

The purpose of this research is to identify and prioritise the factors that can enhance quality of education provided by the Al-Hilal International Islamic School. The data were collected from a purposive sample of 10 parents through interviews and questionnaire survey. Data were analysed using thematic analysis and AHP method for qualitative and quantitative data, respectively. The results from the thematic analysis identified 19 factors from which only 8 were selected for subsequent analysis. These eight factors were Islamic environment, quality of teachers, school discipline, parents' involvement, medium of instruction, school curriculum, class size, and school facilities. The AHP analysis of the quantitative data resulted in prioritising the eight factors according to the parents' judgements. It is concluded that although the factors were derived for $\mathrm{AH}$, they may be also relevant for other Islamic schools that are providing similar services as $\mathrm{AH}$. 


\section{ACKNOWLEDGEMENTS}

The authors are grateful to all the parents whose children are enrolled in AH for their support of this study and providing necessary feedback.

\section{NOTE}

1. This name has been considered to conceal the actual identity of the school.

\section{REFERENCES}

Axford, N., Farrington, D.P., Clarkson, S., Bjornstad, G.J., Wrigley, Z., \& Hutchings, J. (2015). Involving parents in school-based programmes to prevent and reduce bullying: What effect does it have? Journal of Children's Services, 10(3), 242-251. https://doi.org/10.1108/JCS-05-2015-0019

Braun, V., \& Clarke, V. (2006). Using thematic analysis in psychology. Qualitative Research in Psychology, 3(2), 77-101. https://doi.org/10.1191/ 1478088706qp063oa

Burnham, A. (1997). Managing quality in schools: Effective strategies for quality-based school improvement. London: Pearson.

Carnegie Foundation for the Advancement of Teaching. (1992). School choice: A special report. San Francisco, CA: Jossey-Bass Inc Pub.

Fossey, R. (1994). Open enrollment in Massachusetts: Why families choose. Educational Evaluation and Policy Analysis, 16(3), 320-334. https://doi. org/10.3102/01623737016003320

Golden, E., \& Smrekar, C. (2009). Parent satisfaction and involvement in schools of choice. Paper presented at the National Conference on School Choice, 25-27 October 2009, Vanderbilt University, Nashville, Tennessee.

Government of Malaysia. (1996). Malaysia Education Act. Kuala Lumpur: Government of Malaysia.

Government of Malaysia. (2013). Malaysia Education Blueprint (2013-2025). Putrajaya: Government of Malaysia.

Kool, D.D., \& Bekkers, V. (2016). The perceived value-relevance of open data in the parents' choice of Dutch primary schools. International Journal of Public Sector Management, 29(3), 271-287. https://doi.org/10.1108/ IJPSM-02-2016-0022

Kuswadi, S., Barakbah, A.R., \& Nuh, M. (2015). An integrated project-based learning for intelligent control lecture and practice at polytechnics graduate school. In 2015 International Electronics Symposium (IES), 29-30 September 2015, Surabaya, Indonesia (pp. 100-104). https://doi.org/10.1109/ELECSYM. 2015.7380822 
Lycke, L., \& Tano, I. (2017). Building quality culture in higher education. International Journal of Quality and Service Sciences, 9(3/4), 331-346. https://doi.org/10.1108/IJQSS-04-2017-0033

Saaty, T.L. (2008). Decision making with the analytic hierarchy process. International Journal of Service Sciences, 1(1), 83-98. https://doi.org/10.1504/IJSSCI.2008. 017590

Saaty, T.L., \& Peniwati, K. (2008). Group decision making. Pittsburgh, PA: RWS Publications.

Schumacher, M.P. (2011). Parental expectations and satisfaction with charter schools: Evidence from a midwestern city school district. $\mathrm{PhD}$ dissertation, Department of Educational Leadership and Policy Studies, University of Kansas.

Takala, J., Suwansaranyu, V., \& Phusavat, K. (2006). A proposed white-collar workforce performance measurement framework. Industrial Management and Data Systems, 106(5), 644-662. https://doi.org/10.1108/02635570610666421 